\title{
DIGITALCOMMONS
}

—@WAYNESTATE-

Wayne State University

\section{Age-at-Death Estimation for Modern Populations in Mexico and Puerto Rico Through the Use of 3D Laser Scans of the Pubic Symphysis}

Cristina Figueroa Soto

The University of Tennessee, cfiguer1@vols.utk.edu

Bridget F.B. Algee-Hewitt

Stanford University

Guillermo Bravo Morante

University of Granada

Dennis E. Slice

The Florida State University

Dawnie W. Steadman

The University of Tennessee

\section{Recommended Citation}

Figueroa Soto, Cristina; Algee-Hewitt, Bridget F.B.; Bravo Morante, Guillermo; Slice, Dennis E.; and Steadman, Dawnie W., "Age-atDeath Estimation for Modern Populations in Mexico and Puerto Rico Through the Use of 3D Laser Scans of the Pubic Symphysis" (2019). Human Biology Open Access Pre-Prints. 142.

https://digitalcommons.wayne.edu/humbiol_preprints/142

This Open Access Preprint is brought to you for free and open access by the WSU Press at DigitalCommons@WayneState. It has been accepted for inclusion in Human Biology Open Access Pre-Prints by an authorized administrator of DigitalCommons@WayneState. 
Age-at-Death Estimation for Modern Populations in Mexico and Puerto Rico Through the Use of 3D Laser Scans of the Pubic Symphysis

Cristina Figueroa Soto, ${ }^{1 *}$ Bridget F. B. Algee-Hewitt, ${ }^{2}$ Guillermo Bravo Morante, ${ }^{3}$ Dennis E. Slice, ${ }^{4}$ Dawnie W. Steadman ${ }^{1}$

${ }^{1}$ Department of Anthropology, University of Tennessee, Knoxville, Tennessee, USA.

${ }^{2}$ Center for Comparative Studies in Race and Ethnicity, Stanford University, Stanford, California, USA.

${ }^{3}$ Department of Legal Medicine, Toxicology and Psychiatry, University of Granada, Granada, Spain.

${ }^{4}$ Department of Scientific Computing, Florida State University, Tallahassee, Florida, USA.

*Correspondence to: Cristina Figueroa Soto, Department of Anthropology, University of

Tennessee, 1621 Cumberland Avenue Strong Hall, Knoxville, TN, 37996-1525. E-mail:

cfiguer1@vols.utk.edu.

Short Title: Age-at-Death Estimation for Latin American Populations

KEY WORDS: FORENSIC SCIENCE, FORENSIC ANTHROPOLOGY, AGE-AT-DEATH ESTIMATION, PUBIC SYMPHYSIS, MORPHOMETRICS, 3D LASER SCANS, MEXICO, PUERTO RICO, POPULATION VARIABILITY, BIOLOGICAL PROFILE 


\begin{abstract}
Reliable age-at-death estimates from the adult skeleton is of fundamental importance in forensic anthropology, as it contributes to the identity parameters used in a medico-legal death investigation. However, reliable estimates are made difficult by the fact that many traditional aging methods are dependent upon a set of population-specific criteria derived from individuals of European and African descent. The absence of information on the potential differences in the aging patterns of underrepresented, especially Hispanic populations, may hinder our efforts to produce useful age-at-death estimates. In response to these concerns, this study explores the utility of currently available aging techniques, and explores the need, if any, for populationspecific aging method among Hispanic groups. The current study obtained data from two skeletal collections representing modern individuals of Mexican and Puerto Rican origin. Five newly developed computational-shape based techniques utilizing 3D laser scans of the pubic symphysis and one traditional bone-to-phase technique were examined. A validation test of all computational and traditional methods was implemented, and new population-specific equations using the computational algorithms were generated and tested against a sub-sample. Estimated mean ages from the traditional and computational techniques were compared in order to offer practical recommendations for age estimation on cases of Hispanic identity and, in particular, cases presumed to be of Mexican or Puerto Rican individuals. Results from this study suggest that traditional and computational aging techniques applied to the pubic symphysis perform the best with individuals within 35-45 years of age. Levels of bias and inaccuracy increase as chronological age increases, with overestimation of individuals under 35 years of age, and underestimation of individuals over 45 years of age. New regression models provided error rates comparable, and in some occasions, outperformed the original computational models developed
\end{abstract}


on White American males, but age estimates did not significantly improve. This study has shown that population specific models do not necessarily improve age estimates in Hispanic samples. Results do suggest that computational methods can ultimately outperform the Suchey Brooks method and provide improvement in objectivity when estimating age-at-death in Hispanic samples. 
Age-at-death estimation techniques have received considerable attention within the anthropological community, especially among forensic anthropologists, as correctly inferring age-at-death for unknown human remains can aid in making a presumptive identification during the investigative process and can contribute probabilistic evidence towards a positive identification in the medico-legal setting (Algee-Hewitt 2017; Konigsberg et al. 2008; Steadman et al. 2006). Accordingly, age at death is an important component of the biological profile, which also requires the estimation of other such identity parameters as sex, stature, and ancestral background for the skeletonized or fragmentary remains under analysis. However, the estimation of age based on skeletal remains is one of the most challenging biological parameters to estimate. This is in part due to the complex biological variability in aging patterns between and within populations (Kemkes-Grottenthaler 2002), and the methodological and observer-related biases associated with many of the traditional morphological bone-to-phase techniques currently available to the forensic professionals who engage this kind of work across medical-legal fields (Kemkes-Grottenthaler 2002; Kimmerle et al. 2008; Lottering et al 2013; Shirley and Ramirez Montes 2015; Usher 2002).

Common practice among forensic anthropologists involves the use of multiple morphological features in the skeleton to estimate age-at-death, including the pubic symphysis (Brooks and Suchey 1990; Todd 1920), the auricular surface of the ilium (Buckberry and Chamberlain 2002; Lovejoy et al. 1985; Osborne et al. 2004), the sternal end of the fourth rib (Iscan et al. 1984a,1984b; Iscan et al. 1985), and cranial sutures (Meindl and Lovejoy 1985; Nawrocki 1998). According to a recent study by Garvin and Passalacqua (2012), the pubic symphysis is the preferred and most widely used skeletal element for forensic anthropologists when estimating age-at-death. Estimating age from this indicator is complicated by several 
factors, two of which we identify as paramount. First, age-at-death estimation is possible because a correlation exists between chronological and biological age. Yet, this correlation is imperfect because biological age, as a physiological state, is affected by in/extrinsic variables, like genetic makeup, diet, climate, physical activity, socio-economic status, and overall health, such that under different life conditions, individuals will display differences in the magnitude and rate of senescent changes in their skeleton (Kemkes-Grottenthaler 2002). Further, the strength between the correlation of chronological and biological age decreases as age progresses, due, at least in part, to the widening of the range of variation in the morphological changes observed in the age informative areas of the skeleton. For this reason, it is said that each skeleton has its own degree of error (Boldsen et al. 2002).

Second, age estimation can be especially difficult in the forensic context, when the skeleton in question is unknown and not sourced from a closed population, thereby, depending on case-specific circumstances, the individual may be a member of any of many locally or, even, globally distributed populations. Methodological challenges to estimation arise from the fact that most of the established aging techniques were derived from individuals of European, and to a lesser degree, African ancestries from late $19^{\text {th }}$ and mid- $20^{\text {th }}$ century anatomical collections. Since many of these techniques are based on relationships between trait expression and age that were defined using a particular reference sample, there is potential for error when examining individual members or samples of populations who are temporally, geographically, genetically, environmentally and morphologically different from the reference collections. Moreover, whether adopting the more conventional bone-to-phase/stage matching approach (Brooks and Suchey 1990; Buckberry and Chamberlain 2002; Iscan et al. 1984a, 1984b; Iscan et al. 1985; Lovejoy et al. 1985; Osborne et al. 2004; Todd 1920) or implementing the more computationally 
intensive inferential procedures that rely upon new methods for data collection and estimation (Konigsberg 2015; Slice and Algee-Hewitt 2015; Stoyanova et al. 2015; Stoyanova et al. 2017), the quality of the final age result produced by such feature scoring and age prediction techniques depends on the forensic anthropologist's ability to identify and have available the most appropriate reference sample against which to compare the unknown. This issue is especially concerning when attempting to estimate age-at-death for Hispanic individuals. As a multi-group category, Hispanic, encompasses peoples who represent complex genetic or ancestral histories, that have been shaped by often very different periods of migration, colonization, and segregation. According to the US Census, Hispanics are defined as individuals originating from Mexico, Puerto Rico, Cuba, South and Central America, or any other Spanish speaking country that resides in the US (Ennis et al. 2010). Accordingly, Hispanics are known to express a wide range of skeletal morphologies that vary across Latin America (Moreno-Estrada et al. 2013,2014; Rangel-Villalobos et al. 2008). Despite the increasing share of Hispanics in the US demographic in particular, reference samples for Hispanic groups are scarce and, so, population-specific standards are very limited. Only recently have studies sought to produce information estimation criteria for individuals of Mexican nationality. Yet, they have been constrained to the study of sex and ancestry using metric skeletal data from positively identified US-Mexico border crosser fatalities (Fowler and Hughes 2018; Hughes et al. 2018; Ross et al. 2014; Spradley et al. 2015; Spradley et al. 2008; Tise et al. 2013). Due to the small numbers and lack of demographic information (i.e., true age) for these highly targeted analyses, other parameters requiring osteological estimation, such as age-at-death have not been thoroughly examined and validated against the most well-established aging techniques even for these samples. Furthermore, it is still unknown whether or not a population specific approach for age-at-death estimation is needed at 
all for the Hispanic category as a whole, relative to other major populations of forensic interest or for the biogeographic groups - by [micro]region or country - that together make up the category of Hispanic.

Acknowledging these issues, it is critical to ask: Are aging techniques produced using skeletons of European and African descent truly appropriate for aging peoples of Mexican and Puerto Rican origins? If not, does the potential mismatch between target and reference samples produce ill-fitting models and introduce additional sources of error in estimation? Further, to what degree do any such inter-population differences affect final age estimates? Taking up these questions, in this preliminary study, we investigate if significant morphological differences in age-at-death estimation are evident between Mexicans and Puerto Ricans, two groups included within the broad Hispanic category in the United States. The importance of examining groups of Mexican and Puerto Rican origin stems from the fact that their patterns of senescence are poorly understood, the applicability of common age-at-death techniques has not been thoroughly investigated, and rates of error for current techniques have not been reported. It is crucial that efforts are made to reach a clear understanding of age-related changes on these populations, quantify the magnitude of error and bias when estimating age-at-death, and in turn, determine if population specificity in age-at-death estimation is needed.

Currently, the estimation of age greatly depends on the nature of training and expertise of the anthropologist to determine age-related changes in the pubic symphysis, and to visually compare those age-related changes with comparative photographs or cast representing an age range, previously recorded from a group of individual with known ages ( Baccino and Smith 2006 ; Brooks and Suchey 1990; Kimmerly et al. 2008; Slice and Algee-Hewitt 2015). The wellknown problems of subjectivity and increased observed error on traditional age-at-death methods 
was highlighted in a recent survey of forensic anthropologists, where close to half of the respondents in a survey indicated that the choice to use age-at-death estimation from the pubic symphysis using traditional methods, and preferentially the Suchey Brooks method, were mainly dependent on expertise and experience rather than methodology (Garvin and Passalacqua 2012). In order to overcome this issue of subjectivity, several new age-at-death techniques have been proffered (Boldsen at al. 2002; Dudzik and Langley 2015; Milner and Boldsen 2012), including the Slice-Algee-Hewitt Score method (SAH), the Thin plate spline/Bending Energy method (BE), and Ventral Curvature (VC) method (Slice and Algee-Hewitt 2015; Stoyanova et al. 2015; Stoyanova et al. 2017). These techniques together are novel for the fact that they provide a framework that is a fully computational design - estimating age-at-death by quantifying the surface complexity of the bone, as computed from 3D laser scans of the pubic symphysis and modeling the relationship between morphological shape and chronological age. By eliminating the traditional gross morphological assessment, implementing robust shape-based algorithms, and building regression equations for age determination, this framework of analysis seeks to reduce the high degree of variation in method interpretation and low degree of standardization across application and practitioners (Slice and Algee-Hewitt 2015; Stoyanova et al. 2015; Stoyanova et al. 2017). Even though this novel methodology has proven to be a promising tool for the rigorous quantification of age-at-death in European-Americans, its value has not been evaluated from a forensic perspective, for the diversity of contemporary Hispanic populations, which are typically underrepresented in the literature on aging techniques available to forensic practitioners in the United States.

Responding to these concerns, in this study, we focus on age estimation from the pubic symphysis for Hispanics, considering primarily the new fully computational, shape-based 
techniques utilizing 3D laser scans introduced by Slice and Algee-Hewitt and expanded by

Stoyanova and colleagues. Specifically, we perform a validation test of the published

methodology, as implemented with the software, forAge, and we generate population-specific equations for individuals of Mexican and Puerto Rican origin. To determine if group-specific or universal reference samples, and equations, are more appropriate when examining Hispanic groups, even when broadly defined, we also included a large sample from Spain in our analyses. We contextualize these algorithmically derived results in terms of the prevailing, conventional approach to age estimation by testing the ability of the Suchey-Brooks method to yield reliable and accurate age estimates for the same sampling of peoples. We compare the products of these two techniques for all three samples in order to offer practical recommendations for age estimation in forensic anthropology for cases of Hispanic identity and, in particular, presumed Mexican or Puerto Rican origin.

\section{Materials and Methods}

In order to determine the accuracy and reliability of traditional and computational age-at death methods on Hispanic groups, two skeletal samples from two geographical regions in Latin America, Mexico and Puerto Rico, were used. These collections serve as an ideal sample to test

the issues previously outlined. First, these two groups account for $65 \%$ of the Hispanic groups in the US. Thus, our sample speaks to the demographic changes occurring in the US and represents the increasing load of medico legal cases of Hispanic background. Second, each group presents complex population structures with varying ancestry proportions (Moreno-Estrada et al.

2013,2014; Rangel-Villalobos et al. 2008; Salas et al. 2005; Torroni et al. 1995; Via et al. 2011; Wang et al. 2008) and environmental factors affecting each group uniquely (Aguilera et al. 210; 
Carson 2008; Little and Manila 1986; Lopez-Alonzo 2012; Meaney 2010), accounting for potential differences in the age progression of each sample. As skeletal collections from Latin America are scarce, these two rare skeletal collections will help to fill the void in literature on skeletal aging in Hispanic populations. Furthermore, few Latin American samples have been used to quantify bias and error for traditional methods and not yet on computational methods.

The first sample from Mexico belongs to the Universidad Nacional Autónoma de Mexico, School of Medicine, and represents a local population whose birth years range from mid- $20^{\text {th }}$ to late $20^{\text {th }}$ century $(\mathrm{n}=21)$. This skeletal collection originates from medical examiner's cases whose bodies were donated to the Medical Examiner's Office for the sole purpose of medical education and research. In contrast to the U.S., where race (e.g., White, Black, Hispanic, Asian) and place of birth are included in the death certificate, death certificates in Mexico do not provide such options. A physician signing a death certificate must select from the categories of "Mexican national", "other", or "ignore category". Thus, this study included only individuals identified as Mexican nationals on the death certificate.

The second sample is housed at the Instituto de Ciencias Forenses in San Juan, Puerto Rico $(n=60)$. This skeletal collection originates from medical examiner's cases whose bodies were donated to further medical education and research. Similar to the Mexican sample, these individuals represent a local population with birth years from mid-20 th to the beginning of the $21^{\text {st }}$ century. As is the case in Mexico, the death certificate in Puerto Rico does not include an option for the physician to identify race, yet it does provide for indicating the decedent's "citizenship at the time of death". In addition, the physician must include the place of birth, as well as the place of death of the decedent. Individuals categorized as having a Puerto Rican 
citizenship at the time of death were included in this analysis. Due to the small sample size of females available in each collection, only male individuals are included in the study.

As in previous studies examining age-at-death (Lottering et al 2013; Schmitt 2004; Sinha and Gupta 1995; Overbury et al. 2009), only the left side was examined when testing accuracy and reliability. Selection criteria included the completeness of the symphyseal face and absence of pathological conditions in the pelvis. Since changes associated with aging of the pubic symphysis are due to secondary ossification that begins at approximately 18-20 years of age, the minimum age of inclusion in the project was 18 years of age.

Even though it is known that Latin American samples display ancestral contributions from European, Native American, and West Africans, previous genetic studies have shown that Puerto Rican and Mexican groups display variable genetic affinities closely related to populations from Spain (Moreno-Estrada et al. 2013; Rubi-Castellanos et al. 2009; RangelVillalobos et al. 2008; Salas et al. 2005; Torroni et al. 1995; Via et al. 2011Wang et al. 2008). For this reason, a third skeletal sample, sourced from the Medical Examiner's Office in Granada, Spain, was included for tests of group differences. This sample represents a local population from Granada with birth years ranging from late $20^{\text {th }}$ century to early- $21^{\text {st }}$ century.

The age distribution of all three skeletal samples are represented in Figure 1 and Table 1, which includes the sample size and age distribution of each sample. A total of 255 individuals with a mean age of 42.56 years of age were used in this study. When divided by populations, the Mexican sample has a higher mean age of 53 years of age. In contrast, the Puerto Rican and Spanish sample have a similar mean age of 39.87 and 42.22 years of age, respectively. It would be ideal to have a sample that represents all age cohorts appropriately; however, that is not the case in this study. Unfortunately, finding or creating unbiased reference collections for 
individuals of Latin American background has been difficult to achieve. Similar to many reference collections in the U.S., the collections used in this study are skewed towards younger or older individuals of low socioeconomic status with potentially different life histories than the population at large in Puerto Rico and Mexico (Kemkes-Grottenthaler 2002; Usher 2002). However, it is important to acknowledge that the sample size $(\mathrm{n}=255)$ from this study is larger and represents more ages than the original reference sample ( $\mathrm{n}=93)$ for the computational methods developed by Slice and Algee-Hewitt (2015).

The Suchey Brooks age-at-death estimation method was applied to the Puerto Rican and Mexican samples in order to test for accuracy and reliability within samples. The Spanish sample was not available to score at the time of this study. The left pubic symphysis was scored and assigned to one of six phases based on observed characteristics, assessing ridge development and furrows, development and degeneration of the ventral and dorsal aspect of the symphyseal face, presence of lipping, and signs of erosion (Brooks and Suchey 1990). After each individual was scored, a point age estimate (the mean per phase) and an age range (per phase) were assigned to each individual using the published guidelines. To generate the data needed to calculate the three shape measures - the Slice-Algee-Hewitt score (SAH Score), the Bending Energy method (BE), and the Ventral Curvature method (VC) scores - were used following the fully computational framework of Slice and Algee-Hewitt 2015 and Stoyanova et al. 2015 and 2017. 3D laser scans were taken on the left side of the pubic symphysis using the NexEngine 3D Desktop Scanner, 2020i. Each pubic bone was positioned between 7.5 and 9.5 inches away from the scanner box with the symphyseal face being perpendicular to the base of the AutoDrive scanning stand. Oil free clay was used in order to stabilize the bone in the stand. Scan settings were established by using the high definition scanning setting (i.e., a neutral image capture of 16 divisions, and 67K 
points per square inch). After each scan, data manipulation (auto alignment and fusion) was performed with the accompanying software, Scan Studio HD version 1.3.2. The mesh of the symphyseal surface was isolated from the rest of the pubic bone and the surrounding areas of the bone were deleted (tubercle, body of the inferior ramus, pubic body) in order to create a model of the face of the pubic symphysis only.

Each 3D model was saved as a PLY file, which contains the $\mathrm{x}, \mathrm{y}$, and $\mathrm{z}$ coordinates and the information on how the vertices are connected. Each PLY file was uploaded to the forAge software in order to generate an age-at-death value using the built-in reference sample of documented White American males. The algorithms included in the forAge software calculate three shape scores used to estimate age-at-death via regression analysis. The Slice-Algee-Hewitt Score method (SAH) (Slice and Algee-Hewitt 2015) is a variance-based approach that subjects the scan vertices to a principal component analysis. In this method, the third principal component (depth of the symphyseal face) represents the age-progressive transition of the symphyseal face from ridges and furrows towards flattening. As the SAH score algorithm captures the change in variance of the third principal component (PC) eigenvalue, a high score or variance value is associated with younger individuals and a low score is associated with older individuals.

The Thin plate spline/Bending energy (BE) (Stoyanova et al. 2015) score measures the bending energy required for transforming a perfectly flat, infinitely thin plate to match the surface of the pubic symphysis scan. The minimum energy that is required for this bending is expected to account for the changes occurring in the symphyseal phase (i.e., billowed surfaces, flattening, and breakdown of symphyseal phase). In order to produce a BE score, two sets of control points need to be calculated. The first set of points lies on a flat plane (i.e., calculated by a uniform squared mesh on a plane against the scan) and a second set of points that lies across 
the surface of the pubic symphysis (i.e., calculated by a uniform mesh that overlaps the scan morphology). The corresponding points on each mesh have the same $\mathrm{x}$ and $\mathrm{y}$ value, but different $\mathrm{z}$ values (depth). The points on the flat plane have a $\mathrm{z}$ value of 0 , while the points that lie across the surface have a $\mathrm{z}$ value associated with the surface morphology of the scan. After the two sets of control points are calculated, the thin plate spline models the bending of the flat plate to match the mesh from the pubic symphysis morphology. The force needed to bend the plate is calculated as the bending energy score.

The Ventral Curvature method (VC) (Stoyanova et al. 2017) accounts for the progressive formation of a rim around the entire symphyseal surface and its later erosion. As in the BE method, meshes with different densities are generated to cover the entire surface of the pubic symphysis, but the points inside the symphyseal face are deleted, leaving vertices (equidistant semi-landmarks) around the outline of the face. The algorithm in this method uses least squares to find the best fitting circle through the selected semi-landmarks on the symphyseal outline. The curvature of the ventral margin is measured as $1 / \mathrm{r}$; thus, a large radius produces small curvature values, that are associated with younger individuals, and a small radius produces large curvature values that are common for older individuals.

After calculating the scores for all three algorithms, the forAge software was used to generate individual estimates of age-at-death by regression analysis. Three univariate models are based on each raw score, the SAH score, the BE method, and the VC method. In addition, two multivariate models are also included in the software, which combine the SAH with the VC method, and the BE with the VC method. The forAge software provides point estimates of age and does not provide an age range.

Pre-print version. Visit http://digitalcommons.wayne.edu/humbiol/ after publication to acquire the final version. 
In order to evaluate the performance of each method on all Hispanic samples, age estimates for each method (i.e., Suchey Brooks method; the forAge regression equations using the Slice-Algee-Hewitt score method (SAH), Bending Energy method (BE), the Ventral Curvature method (VC) independently, and the two multivariate models using the $\mathrm{SAH}+\mathrm{VC}$ and $\mathrm{BE}+\mathrm{VC}$ methods) were compared against the documented chronological ages for each individual using Student's t-test with a Bonferonni correction and a Wilcoxon Rank-Sum test as a nonparametric equivalent when the samples deviated from normality. The difference between the chronological age and estimated age for all methods was estimated in order to analyze the average age distance. The percentage of age estimates that fall within 5, 10, and 15 years from chronological age were also calculated. Spearman Rho correlation coefficients as a nonparametric equivalent to the Pearson correlation were calculated to determine the relationship between chronological age and estimated mean age for all six methods. Lastly, bias and inaccuracies were calculated for each method using documented chronological ages and estimated ages on combined and separate Mexican and Puerto Rican samples. In order to calculate bias values, the sum of the difference between the estimated age of each method and the chronological age was calculated and divided by the sample size. The bias value demonstrates the average over- or under- estimation of aging by each method. The inaccuracy was calculated by the absolute value of the sum of the difference between the estimated age of each method and the chronological age, which is then divided by the sample size. Inaccuracy values provide a measure of error for each method. Bias and inaccuracies were calculated for the pooled sample (Mexico and Puerto Rico), as well as separately. Bias and inaccuracy values were also calculated by age groups with an equal number of individuals for the pooled sample and the 
Puerto Rican sample. Due to the small sample size, this analysis was not performed on the Mexican sample.

New regression equation models were created. A linear regression analysis with an inverse calibration was performed on the relationship between the estimated age for each method and their respective scores provided by the forAge software. Previous studies have demonstrated that the regression of an age-indicator on age provides unbiased estimates, when using an estimate from a population with a similar distribution (Konigsberg et al. 1994; Konigsberg et al 1998). In addition, a second set of regression equations were built after implementing a log transformation on the raw score to resolve issues of heteroscedasticity (Slice and Algee-Hewitt 2015; Stoyanova et al. 2015, Stoyanova et al. 2017). For each equation, the $\mathrm{R}^{2}$ and Root Mean Square Error (RMSE) were calculated in order to examine how well each model performs. The $\mathrm{R}^{2}$ provides a measure of how much variance is explained by the model and the RMSE provides information regarding how accurate the model predicts the response variable (age). It is worth noting that the RMSE value is in the same unit as the response variable (age=years), thus it can be used to quantify the amount of error for the model. Lower RMSE and $\mathrm{R}^{2}$ higher values indicate a better fit to the model.

Several regression equations were created for (1) the pooled sample from Mexico, Puerto Rico, and Spain and (2) the two samples with the largest sample sizes, Puerto Rico and Spain. When creating a regression equation with two groups, the third sample, here, the sample with the smallest $n$, was used for cross validation. Bias and inaccuracies were calculated to test the accuracy and reliability of the new regression equations on this sample.

\section{Results}


Pooled Samples: Puerto Rico and Mexico. To determine whether or not the estimated age calculated from all six methods were significantly different from the chronological ages, a Student's t-test with a Bonferonni correction $(\alpha=0.05$, $\alpha$ adjusted $=0.008)$, and a Wilcoxon RankSum Test as a non-parametric equivalent were performed. Results indicate that chronological age and estimated age did not differ significantly using the SAH method ( $p$-value =.144), the VC method $(p$-value $=.429)$, the BE + VC method $(p$-value=.042), the SAH + VC method $(p$-value $=.187)$, and the Suchey Brooks method ( $p$-value =.323). The BE method ( $p$-value=3.42e-06) was the only method that presented significant differences between chronological age and estimated age.

The estimated difference between the chronological age and the estimated age for each individual was calculated for all aging methods. The mean age difference for the SAH score, the VC method, and the SAH + VC method respectively are -3.12 ( $\mathrm{SD}=19.03),-2.95(\mathrm{SD}=20.58)$, and -3.13 $(\mathrm{SD}=18.91)$ years for the pooled sample. The corresponding numbers for the $\mathrm{SB}$ method, the $\mathrm{BE}+\mathrm{VC}$ method, and the $\mathrm{BE}$ method respectively are $-6.27(\mathrm{SD}=15.55),-8.67$ $(\mathrm{SD}=18.66)$, and -10.27 years $(\mathrm{SD}=18.41)$. When comparing the average age distance between all aging methods, the BE method tends to have the greatest mean distance. All age distances are represented by negative values, thus indicating that all aging methods tend to underestimate age for the pooled sample.

In addition, results indicate that $25-45 \%$ of the age estimates are within 5 years of the chronological age for the pooled sample on all six methods, while $19-26 \%$ of the age estimates fall within 6 to 10 years of the chronological age. Overall, more than half of the estimates for all aging methods are within 15 years or less of the chronological age. Table 2 presents the aforementioned results in more detail. Spearman Rho correlations were calculated to assess the 
strength of the relationship between chronological age and estimated age on all aging methods. Results indicate that chronological age and the estimated age for the Suchey Brooks method is the highest at .72, followed by the BE+VC method (.48), the SAH+VC method (.44), the SAH Score method (.41), the BE method (.40), and the VC method (.31). All correlations were significant at $\alpha=0.05$. Spearman Rho Rank correlations results are included in Table 3.

Inaccuracy and bias were calculated for each aging method to assess accuracy of the computational and Suchey Brooks methods. When the sample was pooled by group, the SAH method and the $\mathrm{VC}+\mathrm{SAH}$ Score method presented the smallest bias (-2.53 years, -2.71 years, respectively), while the BE method had the greatest bias (-10.86 years). All six methods tended to underestimate age when both samples were analyzed together. The Suchey Brooks method, the $\mathrm{VC}+\mathrm{BE}$ method, and the $\mathrm{BE}$ method underestimated age with the greatest bias (-4.60 years, 9.08 years, and -10.86 years, respectively). Results are presented in descending order in table 4 .

In contrast to the bias results, the Suchey Brooks method had the smallest inaccuracy levels, followed by the $\mathrm{SAH}$ score and the $\mathrm{VC}+\mathrm{SAH}$ score method. The $\mathrm{BE}$ method and $\mathrm{VC}$ method had the largest inaccuracies levels. When the sample was divided into age groups, bias and inaccuracies increased with age and the majority of the methods tend to underestimate age for individuals 45 years of age or older. Individuals at the age group of 35-45 presented the least bias and inaccuracy, with results raging between -0.06 years to -6.27 years for bias levels and 3.46 years to 4.34 years for inaccuracy levels (Table 5).

Puerto Rico. For the Puerto Rican sample, no significant differences exist between chronological age and estimated age when using the SAH Score method ( $p$-value=.463), the VC method ( $p$-value $=.038)$, the VC + SAH method ( $p$-value $=.468)$, and the Suchey Brooks method 
(SB) ( $p$-value=.839). For the BE method ( $p$-value $=.000)$ and the $\mathrm{VC}+\mathrm{BE}$ method $(p$ value $=.003$ ) significant differences were observed between chronological age and estimated age.

The average age distance between the chronological age and the estimated age for the VC method, the VC $+\mathrm{SAH}$ method, and the $\mathrm{SAH}$ method respectively are $0.40,1.46$, and 1.49 years. The corresponding numbers for the Suchey Brooks method, the VC + BE method, and the BE method are $-3.36,-6.57$, and -7.99 years, respectively. Similar to the average age distance of the pooled sample, the BE method remains the method that produces the highest age distance between chronological age and estimated age. Furthermore, results indicate that $12-50 \%$ of the age estimates are within 5 years of the chronological age when both sides are pooled on all six models, while $20-28 \%$ of the age estimates fall within 6 to 10 years of the chronological age. As previously seen when both groups were pooled, more than half of the estimates for all aging methods in the Puerto Rican sample are within 15 years or less of the chronological age. Table 6 presents the results in more detail.

Spearman Rho correlations improved for most of the methods in comparison to the pooled sample (Mexicans and Puerto Ricans). Results indicate that chronological age and estimated age for the Suchey Brooks method, the VC+SAH method, and the SAH score method are the highest at $.73, .56$, and .57 , respectively. The SAH score method correlations increased the most, ranging from .40 when the sample was pooled to .57 when the Puerto Rican sample was examined alone. These results are followed by the $\mathrm{VC}+\mathrm{BE}(.45)$, the $\mathrm{BE}$ method (.38), and the VC method (.28). Similar to previous results, all correlations were significant at $\alpha=0.05$ (Table 7).

When the Puerto Rican sample was analyzed on its own, the Suchey Brooks method, BE method, and $\mathrm{VC}+\mathrm{BE}$ method tended to overestimate age the most. The method that presented the 
least amount of bias was the VC method with 0.40 years. The Suchey Brooks method, the VC + $\mathrm{BE}$ method, and the BE method presented the greatest amount of bias. The method with the greatest bias was the $\mathrm{BE}$ method, which tended to underestimate age. Similar results were observed when the sample was combined by group. Table 8 presents the bias and inaccuracy results in more detail.

As previously seen when inaccuracies were calculated on the pooled sample, the SB method presented the lowest inaccuracy values and the VC method the highest (15.39 years) inaccuracy values. Inaccuracies and bias increased with age when the sample was examined by age groups. The least amount of bias and inaccuracy for all six methods was observed for individuals 35-45 years of age. Bias and inaccuracy increase greatly in individuals ages 65 and older. Overall, results show that bias and inaccuracy for all six methods increased in individuals 30 years of age or younger, and individuals 50 years of age and older. Table 9 presents the bias and inaccuracy values by age group in more detail.

Mexico. When the Mexican sample was analyzed, all computational methods showed significant differences between chronological and estimated age. The Suchey Brooks method was the only method that did not differ significantly between chronological age and estimated age. When the difference between chronological age and estimated age was calculated for the Mexican sample, higher values were encountered than previously presented on the pooled sample and the Puerto Rican sample alone. The mean age distance ranged from -12.55 years when using the VC method, followed by the Suchey Brooks method (-14.59 years), the VC+BE method (-14.67 years), the VC+SAH method (-16.27 years), and the SAH score (-16.32 years). Once again, the BE method presented the highest average distance of -16.75 years between 
chronological age and estimated age. Overall, all methods tend to underestimate age for the Mexican sample. In addition, results indicate that $23-37 \%$ of the age estimates are within 5 years of the chronological age. In contrast to the Puerto Rican sample, more than half of the estimates are within 10 years of the chronological age. Spearman Rho correlations were non-significant for all five computational methods. The Suchey Brooks method yielded a correlation value similar to the previous results, .73 , and significant at $\alpha=0.05$. Tables 10 and 11 presents the aforementioned results in more detail.

In contrast to the Puerto Rican sample, the Mexican sample presents higher bias and inaccuracy values. However, trends in the performance of each method are similar to previous results for the Puerto Rican sample. The Suchey Brooks method has the least amount of bias, with -9.27 years. As in other analyses, the BE method remains the one with the greatest bias (16.74 years). It is worth noting that all methods tend to underestimate age on the Mexican sample.

In contrast to the Puerto Rican sample, the Mexican sample presents higher bias and inaccuracy values. However, trends in the performance of each method are similar to previous results for the Puerto Rican sample. The Suchey Brooks method has the least amount of bias, with -9.27 years. As in other analyses, the BE method remains the one with the greatest bias (16.74 years). It is worth noting that all methods tend to underestimate age on the Mexican sample. The Suchey Brooks method generated the least amount of inaccuracy and the BE method the greatest. In contrast to previous inaccuracy results, these are the highest values presented so far, at 20.57 years. Tables 10-12 give these results in greater detail. 
Regression Equation Models. New models were built using inverse calibration (Konigsberg and Frankenber (1997) after log transformation was applied to the score variable. First, we created 3 regression equations (SAH score, BE Score, and VC score) with the pooled samples from Puerto Rico, Mexico, and Spain. The results of the regression analysis are included in table 13. Results were quite similar for all three shape methods, with RMSE ranging from 14.98 to 15.71 . The log transformation of the score did not produce significant improvements and the results of the raw score versus age produced similar $\mathrm{R}^{2}$.

Second, we created 3 regression equations (SAH score, BE score, and VC score) using the two samples with the largest sample size in order to subject the model to cross-validation analysis. The results of the regression analysis are included in table 14. When the Mexican sample ( $\mathrm{n}=21$ ) was removed from the regression analysis, the RMSE improved. For the BE method, the RMSE decreased from 15.00 years to 14.02 with raw Age vs Score model, whereas with log transformation, it decreased from 14.98 to 14.17. For the SAH score the RMSE values decreased from 15.76 to 13.48 for raw scores and from 15.25 to 13.61 with log transformations. When the VC method was analyzed, the RMSE decreased from 15.71 to 14.61 with raw scores and 15.41 to 14.53 with $\log$ transformation.

$\mathrm{R}^{2}$ remained significantly low for the regression analysis of Puerto Ricans and Spanish groups alone. The only significant improvement in $\mathrm{R}^{2}$ was for the $\mathrm{SAH}$ score, increasing from 0.03 to .16 for raw scores. Because the log transformation did not provide an improvement to the models, the regression of raw score into raw age was used for cross validation analysis with the Mexican sample.

When bias and inaccuracies were examined for the Mexican sample on the new three equations, the SAH method produced the least bias (-6.09) and the smallest inaccuracy with 
16.81 years, followed by the Bending Energy method with a bias of -8.49 , and inaccuracy of 18.96 years. Finally, the Ventral Curvature method produced the greatest bias with -8.75 and an inaccuracy estimate as high as 20.52 (Table 15).

\section{Discussion}

The majority of the methods utilized to estimate age-at-death are based on the premise that progressive changes in bone morphology reflect degenerative processes in the adult skeleton, and chronological age and biological age are strongly positively correlated (Kemkes-Grottenthaler 2002). Despite the classic assumption of uniformitarians in aging patterns and rates, many of these degenerative processes are known to vary among populations, due to differences in growth and development, environment, lifestyle, and genetics (Baccino et al. 1994; KemkesGrottenthaler 2002; Schmitt 2002). As many of the aging techniques key to skeletal analysis in biological, including forensic anthropology, were developed on individuals sampled from populations who differ in both ancestral and life history from peoples of Latin America origin, it is imperative to examine how well these methods perform on individuals originating from Latin America, and conclude if they are appropriate for use in a forensic setting.

Overall, results from this study suggest that traditional and computational aging techniques utilizing the pubic symphysis perform the best for individuals between 35 to 45 years of age. However, the magnitude of error (i.e., inaccuracy) for younger ( $<35$ years of age) and older individuals ( $>45$ years of age) was slightly higher when using the Suchey Brooks method on the pooled sample. Overall, all computational methods performed better on these younger and older individuals. Even though the performance of the computational methods was better in older individuals when compared to the traditional method, the directionality and magnitude of error 
was still significantly high. Results further indicate that in all methods, including traditional and computational, the magnitude and directionality of error increase as chronological age increased. Furthermore, a trend to overestimate younger individuals and underestimate older individuals was seen in all methods.

When exploring the questions concerning population specificity, newly created computational equations with samples of Mexican and Puerto Rican background, did not necessarily improve age estimates. Even though RMSE levels for the new computational equations improved when using the new samples from Puerto Rico and Spain, and the magnitude and directionality of error improved slightly, the improvements are more likely associated with the size and distribution of the reference sample rather than population variation.

Traditional Method. When comparing traditional and computational methods, the Suchey Brooks method performs fairly well when estimating age-at-death on middle aged (mid 30's to late 40 s) individuals for the pooled sample. On average, $44 \%$ or higher of estimated ages fall within 5 years or less of the chronological age. Correlations values between chronological age and estimated age were significantly higher when compared to all five computational methods. When the Suchey Brooks method was applied to the Puerto Rican sample, inaccuracies and bias levels were the lowest. In contrast, the Mexican sample presented the highest bias and inaccuracies values in comparison to the Puerto Rican sample. These results can be explained by several factors, including the age distribution of the reference and test sample, and the calculation of bias and inaccuracy from the mean ages that originate from the age distribution.

First, previous publications have shown that the Suchey Brooks method tends to be more accurate when aging younger individuals than older ones (Miranker 2016; Rissech et al. 2011; 
Hens et al. 2008). The Suchey Brooks method is a regression-based model in which the test sample tends to mimic the age distribution of the reference sample used to create the method. This trend is due to the reference sample of the method, which has far more young adults $(<45$ years of age) than older adults (45 to 90 years of age). If younger adults are the only ones well represented in a reference sample, the method will have lower mean ages for each phase, disregarding potential informative age-related changes within older individual. This means that the mean age for each phase on the Suchey Brooks method is skewed towards younger individuals, and consequently, lower mean ages. Second, this issue has the potential of increasing bias and inaccuracy for the age groups that are underrepresented in the reference sample. For this study, the Puerto Rican sample has a greater proportion of younger individuals ( $<40$ years of age with a mean age of 39.87) than does the Mexican sample, accounting for the generally good performance of the Suchey Brooks method in the Puerto Rican sample. Simply said, the age distribution of the Puerto Rican sample is more similar to the Suchey Brooks reference sample than the Mexican sample. The high inaccuracy and bias values that resulted from using the Suchey Brooks method on the Mexican sample can be explained by the aforementioned trends, as the Mexican sample is mostly composed of individuals over 50 years of age, with a mean age of 53.05. Individuals above the age of 50 years of age are underrepresented in the reference sample. It is expected for bias and inaccuracy to be lower when the Suchey Brooks method is tested on a population with a similar age-at-death structure than the reference sample.

When results from this study are compared to previously published studies, it is surprising to note that the directionality and magnitude of error presented between estimated mean age and chronological age in this study are much lower than for other studies. Miranker 
(2016) has shown that on a sample of 131 white males from the William M. Bass Donated Collection, the Suchey Brooks method presented bias levels as high as -20.01 and measures of inaccuracy of 20.3 years. It is worth noting that the highest bias and inaccuracy levels found in the current analysis for the Suchey Brooks method are -9.27 and 13.07 years, respectively, in the Mexican group alone. Schmitt (2004) presented bias levels of -14.5 and inaccuracies measures of 17.2 years for a small sample $(n=37)$ of Thai males using the Suchey Brooks method. In contrast, when a large $(n=202)$ Italian sample was analyzed by Hens and colleagues (2008), levels of bias (-11.1) and inaccuracies (13.6 years) were comparable to values presented in this study. Although different levels of bias and inaccuracies have been reported for other populations across the world, trends of overestimating individuals younger than 40 years of age and underestimating older individuals were similar across all studies. Furthermore, all previous studies, including the current study, showed that the average estimation of error increased with the progression of chronological age.

Computational Methods. Overall, multivariate methods (BE+VC, SAH+VC) performed better than their univariate counterparts on all samples. The results presented in this study are consistent with Stoyanova et al. (2017), who demonstrated a significant improvement in age-atdeath estimation when the $\mathrm{SAH}$ score, $\mathrm{BE}$, and $\mathrm{VC}$ methods were combined in a multivariate method. When examining the univariate regression models against the chronological age of the sample, the SAH score outperformed the BE and the VC methods. Results in this study consistently demonstrated that the magnitude and directions of error for the BE and $\mathrm{VC}$ methods were the highest among all methods. These results were consistent with Stoyanova's results on 
White American males, which demonstrated that the SAH score usually outperformed the BE method, and the VC method alone did not outperform neither of the previous methods.

When comparing all computational methods against both groups, the Puerto Rican sample performed better on all five methods. It would be tempting to argue that population differences are driving the better performance of the Puerto Rican sample against the Mexican sample. However, several issues with the distribution of the sample might provide a better explanation as to why the Puerto Rican sample is performing better. First, prior publications have demonstrated that all five computational methods perform better on younger samples, thus attributing the low level of inaccuracies to the Puerto Rican sample (Slice and Algee-Hewitt 2015; Stoyanova et al. 2016; Stoyanova et al. 2017; Koterova et al. 2018). All five computational methods were developed on a sample of 93 White American males and half of those individuals were between the ages of 40 to 90 years of age, thus implying that the reference sample is slightly skewed towards younger individuals $(16-39$ years, $n=48 ; 40-90$ years, $n=45)$. As previously mentioned, the Puerto Rican sample distribution is skewed towards younger individuals, while the Mexican sample is composed of older individuals. Furthermore, the Mexican sample is quite small in comparison to the Puerto Rican sample, so this might be the reason why no significant improvements are seen when the sample is pooled. Second, even though computational methods are being used to characterize the shape and morphology of the pubic symphysis, the age of each individual is calculated using a linear regression model, similar to the one used in the Suchey Brooks method. Thus, the same issues of producing age estimates for an unknown that are biased on the direction of the composition of the ages of the reference sample are going to be encountered. 
When the magnitude and directionality of error were compared against prior studies analyzing the same computational methods (Stoyanova et al. 2016), overall, values are not too different. Inaccuracy values presented for the original study (Stoyanova et al. 2016; Stoyanova et al. 2017) range from 10.79 years to 12.86 years, while inaccuracy values for the pooled Mexican and Puerto Rican sample range from 12.59 to 15.52 years. Bias values for both samples combined ranges from -0.02 to 7.70 on all five computational samples, while Stoyanova et. al. (2016) reported ranges between -1.82 to -2.73 years for their entire dataset. While the inaccuracy and bias levels are higher than the original reporting, it is worth noting that the original computational methods and linear regression models were developed using White American males. These are the same models used to calculate the estimated ages for the Latin American samples. Even though different trends were observed in the values of inaccuracies for both populations on all methods, inaccuracies values for all methods show that the average estimation error increased with the progression of age. Thus, it was demonstrated that as age increases, all methods tend to present more error.

A different study using 96 male pubic symphyses from four European collections provided bias ranging from -8.43 (VC method) to -15.67 (BE+VC (Kotevora et al. 2018). Inaccuracy values for the aforementioned study ranged from 14.15 to 16.96 , which were much higher than when compared to the current study and the Stoyanova study. It is interesting to note that the study using European males suggested that the multivariate analysis using the SAH+VC method and $\mathrm{BE}+\mathrm{VC}$ method have the highest magnitude and directionality of error. Similar to previous studies, inaccuracy values for all methods showed that the average estimation error increased with the progression of age. It is worth noting that the inaccuracy values for their age categories were much higher than other studies, including this one. 
Some explanations for the higher error values on the Kotevora et al. (2018) study include the mean age distribution of the sample and different post-processing steps after laser scanning, like cleaning and trimming the pubic symphysis. First, as previously mentioned, all computational methods perform better on younger individuals. The sample used in the Kotevora et al. (2018) study is slightly skewed towards older individuals, with more than half of the sample between the ages of 41 to 83 years of age, with a mean age of 56.90 years. Kotevora and colleagues acknowledge that the higher error in directionality and magnitude is due to the composition of the sample.

A second potential source of error could be the use of a different scanner and postprocessing steps. Kotevora et al. (2018) used a less known structured light scanner (HP 3D Structure Light Scanner Pro S2), that utilizes projected light patterns that captures the threedimensional shape of the pubic symphysis. In contrast to the NextEngine 3D desktop scanner, the structured light scanner is known for providing a higher resolution with less scanning time. Previous publications have tested the structured light scanner's accuracy and reliability in human and non-human bones when examining sharp force and blunt force trauma (Gonzalez et al. 2015; Edwards and Rogers 2017), but it is unknown whether the output of these two scanners can be a source of error. However, when using the computational methods, the symphyseal phase needs to be manually selected from the rest of the bone, and the cleaning process depends to some extent on the resolution of the scan data. Thus, it is safe to assume that the better the resolution provided by the scanner, the less margin of error should be encountered when manually selecting the symphyseal phase. However, after laser scanning the pubic symphysis, the symphyseal face needs to be manually trimmed by the practitioner. Jieun and colleagues (2017) have shown that even though the sources of error are minimal when comparing results from four practitioners 
with different levels of experiences, several potential sources of error are still present, like the lack of delimitation of the extremities on younger individuals when trimming the pubic symphysis, the presence or absence of a tubercle, and deciding which side is the ventral or dorsal side when loading the file on the forAge software. These are potential sources of error if the symphyseal face is not properly trimmed.

Our current study has shown that population specific models do not necessarily improve age estimates. New regression models built here using the Puerto Rican and Spanish samples provided error rates comparable to the original computational models developed on White American males. Stoyanova and colleagues (2017) report results for the SAH score method with an $\mathrm{R}^{2}$ value of 0.478 and a RMSE value of 14.15 years. We show that when new regression equations were created with the Puerto Rican, Mexican, and Spanish samples, the $\mathrm{R}^{2}$ value decreased significantly (0.03); however, the RMSE value was comparable to the original study at 15.25 years. Similar results were obtained for the Bending Energy method and the Ventral Curvature method, where the $\mathrm{R}^{2}$ was significantly lower, but the RMSE was close to the original values of Stoyanova et al. (2017).

It is worth nothing that when the Mexican sample was removed from the new regression models, the RMSE values decreased significantly. The new RMSE outperform the regression models of Stoyanova by 2.36 years for the Bending Energy method, 0.67 years for the SAH score method, and 1.93 years for the Ventral Curvature method. All of the new regression models were significant at $p<0.05$; however, the $\mathrm{R}^{2}$ decreased significantly. The new models were subjected to cross validation using the Mexican sample as the unknown. Bias and inaccuracy values were calculated for all three computational methods and overall, no significant improvement was seen for the inaccuracy values, with most values ranging between 18 to 20 
years. However, bias values improved significantly, decreasing from values as high as -16 to -

6.09. For this reason, we recommend the use of the new model using the Puerto Rican and Spanish sample for future age-at-death estimation on Hispanic individuals.

Even though new regression models provide significant improvement in the RMSE, it is possible that this improvement is due to sample size rather than population variability. Stoyanova et al. 2017 demonstrated that with the addition of 40 samples substantial improvement in the $\mathrm{R}^{2}$ and RMSE is gained for the SAH score method, BE method, and VC method. These original computational methods are based on 93 samples, while our new regression models for the Spanish and Puerto Rican samples were created with almost double the sample size $(n=234)$. We argue that our preliminary analyses indicate that current computational framework is a reasonable option for estimating age-at-death on samples originating from Mexico and Puerto Rico. The results presented here demonstrate that by increasing the sample size of the reference sample, it might be possible to increase the $\mathrm{R}^{2}$ and decrease the RMSE. In turn, by providing such low RMSE levels, we contend that such computational methods could ultimately outperform the Suchey Brooks method and provide improvement in objectivity when estimating age-at-death in Hispanic samples.

\section{Acknowledgments}

This project was supported by Award No. 2015-DN-BX-K010 awarded by the National Institute of Justice, Office of Justice Programs, U.S. Department of Justice. The opinions, findings, and conclusions or recommendations expressed in this publication/program/exhibition are those of the authors and do not necessarily reflect those of the Department of Justice. The authors acknowledge the following individuals for their assistance and access to the skeletal material 
examined in this study: Dr. Lorena Valencia Caballero, Dr. Edwin Crespo Torres, and Dr. Diego Pineda Martinez.

Received 16 January 2019; accepted for publication 9 March 2019. 


\section{Literatured Cited}

Aguilera, O., A. F. Fernández, A. Muñoz et al. 2010. Epigenetics and environment: A complex relationship. J. Appl. Physiol. (1985) 109:243-251.

Algee-Hewitt, B. F. B. 2017. Age estimation in modern forensic anthropology: Statistical considerations. In Forensic Anthropology: A Comprehensive Introduction, M.T. Tersigni-Tarrant and N. Shirley, eds. Boca Raton, FL: Taylor \& Francis Group, 181230.

Baccino, E., and A. Schmitt. 2006. Determination of adult age at death in the forensic context. In Forensic Anthropology and Medicine, A. Schmitt, E. Cunha, and J. Pinheiro, eds. Totowa, NJ: Humana Press, 259-280.

Boldsen, J. L., G. R. Milner, L. W. Konigsberg et al. 2002. Transition analysis: A new method for estimating age from skeletons. In Paleodemography: Age Distributions from Skeletal Samples, R. D. Hoppa and J. W. Vaupel, eds. Cambridge: Cambridge University Press, 73-106.

Brooks, S., and J. M. Suchey. 1990. Skeletal age determination based on the os pubis: A comparison of the Acsádi-Nemeskéri and Suchey-Brooks methods. Hum. Evol. 5:227238.

Buckberry, J. L., and A. T. Chamberlain. 2002. Age estimation from the auricular surface of the ilium: A revised method. Am. J. Phys. Anthropol. 119:231-239.

Bullock, M., L. Márquez, P. Hernández et al. 2013. Paleodemographic age-at-death distributions of two Mexican skeletal collections: A comparison of transition analysis and traditional aging methods. Am. J. Phys. Anthropol. 152:67-78. 
Carson, S. A. 2008. The stature and body mass of Mexicans in the nineteenth-century United States. J. Interdiscip. Hist. 39:211-232.

Dudzik, B., and N. R. Langley. 2015. Estimating age from the pubic symphysis: A new component-based system. Forensic Sci. Int. 257:98-105.

DiGangi, E. A., J. D. Bethard, E. H. Kimmerle et al. 2009. A new method for estimating age-atdeath from the first rib. Am. J. Phys. Anthropol. 138:164-176.

Edwards J., and T. Rogers. 2017. The accuracy and applicability of 3D modeling and printing blunt force cranial injuries. J. Forensic Sci. 63:683-691.

Ennis, S. R., M. Ríos-Vargas, and N. G. Albert. 2011. The Hispanic Population: 2010. 2010 Census Briefs.

Fowler, G., and C. Hughes. 2018. Development and assessment of postcranial sex estimation method for a Guatemalan population. J. Forensic Sci. 63:490-496.

Garvin, H. M., and N. V. Passalacqua. 2012. Current practices by forensic anthropologists in adult skeletal age estimation. J. Forensic Sci. 57:427-433.

Gilbert, B. M., and T. W. McKern. 1973. A method for aging the female os pubis. Am. J. Phys. Anthropol. 38:31-38.

González, M. Á. M, J. Yravedra, D. González-Aguilera et al. 2015. Micro-photogrammetric characterization of cut marks on bone. J. Archaeol. Sci. 62:128-142.

Hens, S. M., E. Rastelli, and G. Belcastro. 2008. Age estimation from the human os coxa: A test on a documented Italian collection. J. Forensic Sci. 53:1,040-1,043.

Hughes, C. E., B. Dudzik, B. F. B. Algee-Hewitt et al. 2018. Understanding (mis) classification trends of Latin Americans in Fordisc 3.1: Incorporating cranial morphology, 
microgeographic origin, and admixture proportions for interpretation. J. Forensic Sci. 64:353-366.

Iscan, M. Y., S. R. Loth, and R. K. Wright. 1984a. Metamorphosis at the sternal rib end: A new method to estimate age at death in white males. Am. J. Phys. Anthropol. 65:147-156.

Iscan, M. Y., S. R. Loth, and R. K. Wright. 1984b. Age estimation from the rib by phase analysis: White males. J. Forensic Sci. 29:1,094-1,104.

Iscan, M. Y., S. R. Loth, and R. K. Wright. 1985. Age estimation from the rib by phase analysis: White females. J. Forensic Sci. 30:853-863.

Kemkes-Grottenthaler, A. 2002. Aging through the ages: Historical perspectives on age indicator methods. In Paleodemography: Age Distributions from Skeletal Samples, R. D. Hoppa and J. W. Vaupel, eds. Cambridge: Cambridge University Press, 48-72.

Kim, J., B. F. B Algee-Hewitt, D. Stoyanova et al. 2019. Testing reliability of the computational age-at-death estimation methods between five observers using threedimensional image data of the pubic symphysis. J. Forensic Sci. 64:507-518.

Kimmerle, E. H., D. A. Prince, and G. E. Berg. 2008. Inter-observer variation in methodologies involving the pubic symphysis, sternal ribs, and teeth. J. Forensic Sci. 53:594-600.

Konigsberg, L. W. 2015. Multivariate cumulative probit for age estimation using ordinal categorical data. Ann. Hum. Biol. 42:368-378.

Konigsberg, L. W., S. R. Frankenberg, and R. B. Walker. 1994. Regress what on what?:

Paleodemographic age estimation as a calibration problem. In Integrating Archaeological Demography: Multidisciplinary Approaches to Prehistoric Population, R. R. Paine, ed. Carbondale, IL: Southern Illinois University, 64-88. 
Konigsberg, L. W., S. M. Hens, L. M. Jantz et al. 1998. Stature estimation and calibration: Bayesian and maximum likelihood perspectives in physical anthropology. Am. J. Phys. Anthropol. 107:65-92.

Konigsberg, L. W., N. P. Herrmann, D. J. Wescott et al. 2008. Estimation and evidence in forensic anthropology: Age-at-death. J. Forensic Sci. 53:541-557.

Kotěrová, A., J. Velemínská, E. Cunha et al. 2018. A validation study of the Stoyanova et al. method (2017) for age-at-death estimation quantifying the 3D pubic symphyseal surface of adult males of European populations. Int. J. Legal Med. 133:1-10.

Little, B. B., and R. M. Malina. 1986. Gene flow and variation in stature and craniofacial dimensions among indigenous populations of Southern Mexico, Guatemala, and Honduras. Am. J. Phys. Anthropol. 70:505-512.

López-Alonso, M. 2012. Measuring Up: A History of Living Standards in Mexico, 1850-1950. Stanford, CA: Stanford University Press.

Lottering, N., D. M. Macgregor, M. Meredith et al. 2013. Evaluation of the Suchey-Brooks method of age estimation in an Australian subpopulation using computed tomography of the pubic symphyseal surface. Am. J. Phys. Anthropol. 150:386-399.

Lovejoy, C. O., R. S. Meindl, T. R. Pryzbeck et al. 1985. Chronological metamorphosis of the auricular surface of the ilium: A new method for the determination of adult skeletal age at death. Am. J. Phys. Anthropol. 68:15-28.

Meaney, M. J. 2010. Epigenetics and the biological definition of gene $\times$ environment interactions. Child Dev. 81:41-79. 
Meindl, R. S., and C. O. Lovejoy. 1985. Ectocranial suture closure: A revised method for the determination of skeletal age at death based on the lateral-anterior sutures. Am. J. Phys. Anthropol. 68:57-66.

Milner, G. R., and J. L. Boldsen. 2012. Transition analysis: A validation study with known-age modern American skeletons. Am. J. Phys. Anthropol. 148:98-110.

Miranker, M. 2016. A comparison of different age estimation methods of the adult pelvis. $J$. Forensic Sci. 61:1,173-1,179

Moreno-Estrada, A., C. R. Gignoux, J. C. Fernández-López et al. 2014. Human genetics: The genetics of Mexico recapitulates Native American substructure and effects biomedical traits. Science 344:1,280-1,285.

Moreno-Estrada, A., S. Gravel, F. Zakharia et al. 2013. Reconstructing the population genetic history of the Caribbean. PLoS Genet. 9:e1003925.

Nawrocki, S. P. 1998. Regression formulae for the estimation of age form cranial suture closure. In Forensic Osteology: Advances in the Identification of Human Remains, K. Reichs, ed. Springfield, IL: CC Thomas, 276-292.

Osborne, D. L., T. L. Simmons, and S. P. Nawrocki. 2004. Reconsidering the auricular surface as an indicator of age at death. J. Forensic Sci. 49:905-911.

Overbury, R. S., L. L. Cabo, D. C. Dirkmaat et al. 2009. Asymmetry of the os pubis: Implications for the Suchey-Brooks method. Am. J. Phys. Anthropol. 139:261-268

Rangel-Villalobos, H., J. F. Muñoz-Valle, A. González-Martín et al. 2008. Genetic admixture, relatedness, and structure patterns among Mexican populations revealed by the $\mathrm{Y}$ chromosome. Am. J. Phys. Anthropol. 135:448-461. 
Rissech, C., J. Wilson, A. P. Winburn et al. 2012. A comparison of three established age estimation methods on an adult Spanish sample. Int. J. Legal Med. 126:145-155.

Ross, A., D. E. Slice, and D. H. Ubelaker. 2014. Population affinities of Hispanic crania: Implications for forensic identification. In Biological Affinity in Forensic Identification of Human Skeletal Remains: Beyond Black and White, G. E. Berg and S. C. Ta'ala, eds. Boca Raton, FL: CRC Press, 155-164.

Salas, A., M. Richards, M. V. Lareu et al. 2005. Shipwrecks and founder effects: Divergent demographic histories reflected in Caribbean mtDNA. Am. J. Phys. Anthropol. 128:855-860.

Schmitt, A. 2004. Age-at-death assessment using the os pubic and the auricular surface of the ilium: A test on an identified Asian sample. Int. J. Osteoarchaeol. 14:1-6.

Shirley, N. R., and P. A. Ramirez Montes. 2015. Age estimation in forensic anthropology: Quantification of observer error in phase versus component-based methods. J. Forensic Sci. 6:107-111.

Sinha, A., and V. Gupta. 1995. A study on estimation of age from pubic symphysis. Forensic Sci. Int. 75:73-78.

Slice, D. E., and B. F. B. Algee-Hewitt. 2015. Modeling bone surface morphology: A fully quantitative method for age-at-death estimation using the pubic symphysis. J. Forensic Sci. 60:835-842.

Spradley, M. K., B. E. Anderson, and M. L. Tise. 2015. Postcranial sex estimation criteria for Mexican Hispanics. J. Forensic Sci. 60:S27-S31. 
Spradley, M. K., R. L. Jantz, A. Robinson et al. 2008. Demographic change and forensic identification: Problems in metric identification of Hispanic skeletons. J. Forensic Sci. $53: 21-28$.

Steadman, D. W., B. J. Adams, and L. W. Konigsberg. 2006. Statistical basis for positive identification in forensic anthropology. Am. J. Phys. Anthropol. 131:15-26.

Stoyanova, D., B. F. B. Algee-Hewitt, J. Kim et al. 2017. A fully computational framework for age-at-death estimation from the adult skeleton: Surface and outline analysis of threedimensional laser scans of the pubic symphysis. J. Forensic Sci. 62:1,434-1,444.

Stoyanova, D., B. F. B. Algee-Hewitt, and D. E. Slice. 2015. An enhanced computational method for age-at-death estimation based on the pubic symphysis using 3D laser scans and thin plate splines. Am. J. Phys. Anthropol. 158:431-40.

Tise, M. L., M. K. Spradley, and B. E. Anderson. 2013. Postcranial sex estimation of individuals considered Hispanic. J. Forensic Sci. 58:S9-S14.

Todd, T. W. 1920. Age changes in the pubic bone. I: The male white pubis. Am. J. Phys. Anthropol. 3:285-334.

Torroni, A., M. D. Brown, M. T. Lott et al. 1995. African, Native American, and European mitochondrial DNAs in Cubans from Pinar del Rio Province and implications for the recent epidemic neuropathy in Cuba. Hum. Mutat. 5:310-317.

Usher, B. M. 2002. Reference samples: The first step in linking biology and age in the human skeleton. In Paleodemography: Age Distributions from Skeletal Samples, R. D. Hoppa and J. W. Vaupel, eds. Cambridge: Cambridge University Press, 29-47.

Via, M., C. R. Gignoux, L. A. Roth et al. 2011. History shaped the geographic distribution of genomic admixture on the island of Puerto Rico. PLoS One 6:e16513. 
Wang, S., N. Ray, W. Rojas et al. 2008. Geographic patterns of genome admixture in Latin American Mestizos. PLoS Genet. 4:e1000037. 
Table 1. Descriptive Statistics for All Samples

\begin{tabular}{|l|c|c|c|c|c|}
\hline \multicolumn{1}{|c|}{ Sample } & $\mathrm{n}$ & Min Age & Median Age & Mean Age & Max Age \\
\hline Pooled (Mexico, Puerto Rico, & 255 & 18 & 41 & 42.56 & 90 \\
\hline Mexico & & & & & \\
\hline Puerto Rico & 21 & 18 & 52 & 53 & 90 \\
\hline Spain & 60 & 19 & 33.50 & 39.87 & 82 \\
\hline
\end{tabular}

Table 2. For Each Method, the Estimated Percent of Age that Falls within 5, 10, and 15 Years of the Chronological Age for the Pooled Sample

\begin{tabular}{|l|c|c|c|c|c|c|}
\hline \multicolumn{7}{|c|}{ PR and Mexico } \\
\hline Difference & Bending & SAH & Ventral & BE+ & SAH+ & Suchey \\
& Energy & Score & Curvature & VC & VC & Brooks \\
& (BE) & & $($ VC) & & & \\
\hline$\leq 5$ & $32.09 \%$ & $29.62 \%$ & $24.69 \%$ & $32.09 \%$ & $28.39 \%$ & $44.44 \%$ \\
\hline 6 to 10 & 22.22 & 20.98 & 18.51 & 25.92 & 22.22 & 19.75 \\
\hline 11 to 15 & 9.87 & 16.04 & 17.28 & 11.11 & 14.81 & 7.40 \\
\hline$\geq 16$ & 38.27 & 33.33 & 39.50 & 30.86 & 33.33 & 28.39 \\
\hline
\end{tabular}


Table 3. Mean Values of the Age-Estimates for Each Computational Method and the Spearman's Rank Correlation between the Chronological Age and the Estimated Age for the Pooled Sample

\begin{tabular}{|c|c|c|c|}
\hline Method & Mean & Correlation & Sign. Prob. \\
\hline Chronological Age & 43.28 & - & - \\
\hline Bending Energy & 33.01 & 0.404 & .0001 \\
\hline SAH Score & 40.16 & 0.410 & .0001 \\
\hline Ventral Curvature & 40.33 & 0.316 & .004 \\
\hline Bending Energy + Ventral Curvature & 34.61 & 0.485 & $4.41 \mathrm{e}-06^{*}$ \\
\hline SAH + Ventral Curvature & 40.15 & 0.441 & $3.724 \mathrm{e}-05^{*}$ \\
\hline Suchey Brooks & 37.01 & 0.722 & $2.7 \mathrm{e}-14^{*}$ \\
\hline
\end{tabular}

$(*$ =significantly different with a $\alpha=0.05)$

Table 4. Bias and Inaccuracy Values Calculated for the Pooled Sample

\begin{tabular}{|c|c|c|}
\hline Method & Bias & Inaccuracy \\
\hline SAH Score & -2.53 & 13.87 \\
\hline SAH+ VC & -2.71 & 13.66 \\
\hline Ventral Curvature & -2.95 & 15.47 \\
\hline Suchey Brooks & -4.60 & 9.98 \\
\hline BE+ VC & -9.08 & 14.46 \\
\hline Bending Energy & -10.86 & 15.58 \\
\hline
\end{tabular}


Table 5. Bias and Inaccuracy Values Calculated for Each Method, by Age Group, on the Pooled Sample

\begin{tabular}{|c|c|c|c|c|c|c|c|c|c|c|c|c|}
\hline & \multicolumn{2}{|c|}{$\begin{array}{l}\text { SAH } \\
\text { Score }\end{array}$} & \multicolumn{2}{|c|}{ BE } & \multicolumn{2}{|c|}{$\begin{array}{c}\text { Ventral } \\
\text { Curvature }\end{array}$} & \multicolumn{2}{|c|}{$\begin{array}{c}\text { SAH + } \\
\text { Vent Curv }\end{array}$} & \multicolumn{2}{|c|}{$\begin{array}{c}\text { BE + } \\
\text { Vent Curv }\end{array}$} & \multicolumn{2}{|c|}{$\begin{array}{l}\text { Suchey } \\
\text { Brooks }\end{array}$} \\
\hline $\begin{array}{l}\text { Age } \\
\text { At } \\
\text { death }\end{array}$ & Bias & Inacc. & Bias & Inacc. & Bias & Inacc. & Bias & Inacc. & Bias & Inacc. & Bias & Inacc. \\
\hline$<25$ & 2.69 & 3.51 & 1.81 & 3.03 & 6.67 & 6.67 & 1.49 & 2.37 & 2.69 & 3.33 & 1.71 & 4.14 \\
\hline $26-34$ & 6.47 & 6.80 & 2.08 & 3.39 & 5.08 & 5.16 & 2.41 & 3.62 & 6.37 & 6.62 & 6.57 & 7.06 \\
\hline $35-45$ & 0.28 & 3.75 & -3.61 & 3.82 & 1.01 & 4.20 & -2.66 & 4.34 & 0.80 & 3.46 & -0.18 & 3.97 \\
\hline $46-65$ & -3.82 & 5.22 & -9.9 & 9.9 & -6.66 & 6.89 & -7.94 & 8.25 & -4.23 & 4.78 & -9.75 & 10.46 \\
\hline
\end{tabular}

Table 6. For Each Method, the Percent of Age Estimated That Falls within 5, 10, And 15 Years of the

Chronological Age for the Puerto Rican Sample

\begin{tabular}{|l|c|c|c|c|c|c|}
\hline \multicolumn{7}{|c|}{ Puerto Rico } \\
\hline Difference & Bending & SAH & Ventral & BE+ & SAH+ & Suchey \\
& Energy & Score & Curvature & VC & VC & Brooks \\
& (BE) & & $($ VC) & & & \\
\hline$\leq 5$ & $33.03 \%$ & $11.61 \%$ & $22.32 \%$ & $26.79 \%$ & $14.29 \%$ & $50.0 \%$ \\
\hline 6 to 10 & 27.67 & 19.64 & 23.21 & 24.11 & 22.32 & 25.0 \\
\hline 11 to 15 & 13.39 & 18.75 & 16.07 & 11.61 & 15.18 & 8.93 \\
\hline$>15$ & 25.89 & 50.00 & 41.07 & 37.50 & 48.21 & 16.1 \\
\hline
\end{tabular}


Table 7. Mean Values of the Age-Estimates for Each Computational Method and the Spearman's Rank Correlation between the Chronological and Estimated Age for the Puerto Rican Sample

\begin{tabular}{|c|c|c|c|}
\hline Age-at-Death & Mean & Correlation & Sign. Prob. \\
\hline Chronological Age & 39.87 & - & - \\
\hline Bending Energy & 31.87 & 0.385 & $0.002^{*}$ \\
\hline SAH Score & 41.36 & 0.563 & $2.781 \mathrm{e}-06^{*}$ \\
\hline Ventral Curvature & 40.27 & 0.284 & $0.0293^{*}$ \\
\hline Bending Energy + Ventral Curvature & 33.29 & 0.454 & $0.0002^{*}$ \\
\hline SAH +Ventral Curvature & 41.33 & 0.573 & $1.65 \mathrm{e}-06^{*}$ \\
\hline Suchey Brooks & 36.51 & 0.732 & $2.99 \mathrm{e}-11^{*}$ \\
\hline
\end{tabular}

(* =significantly different with an $\alpha=0.05$ )

Table 8. Bias and Inaccuracy Values Calculated for Each Method on the Puerto Rican Sample

\begin{tabular}{|c|c|c|}
\hline Method & Bias & Inaccuracy \\
\hline Suchey Brooks & -3.36 & 9.16 \\
\hline SAH Score & 1.49 & 12.34 \\
\hline Bending Energy & -7.99 & 13.36 \\
\hline SAH Score +Ventral Curvature & 1.46 & 12.04 \\
\hline Bending Energy + Ventral Curvature & -6.57 & 12.70 \\
\hline Ventral Curvature & 0.40 & 14.91 \\
\hline
\end{tabular}


Table 9. Bias and Inaccuracy Values Calculated for Each Method, by Age Group, on the Puerto Rican Sample

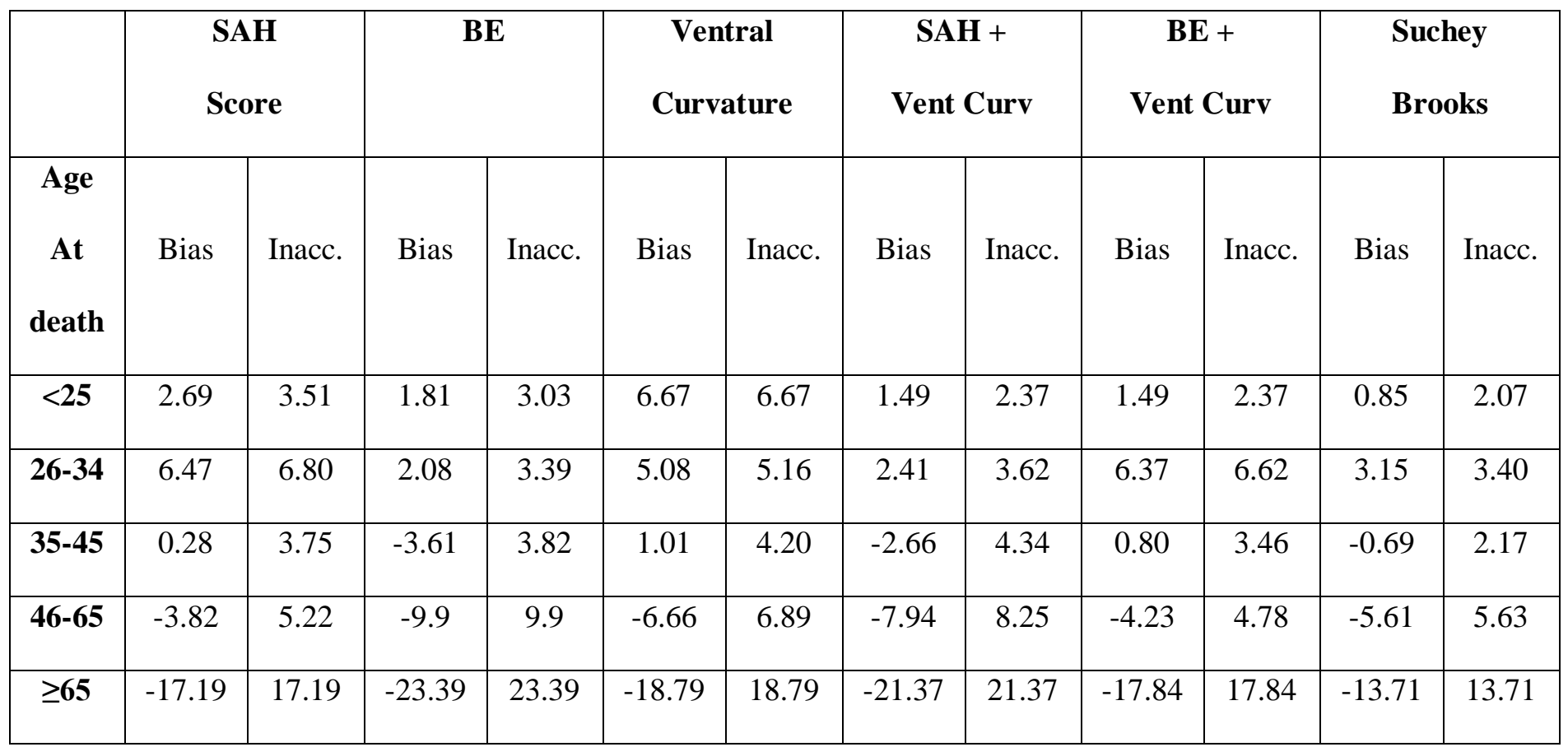

Table 10. For Each Method, the Percent of Age Estimated That Falls within 5, 10, And 15 Years of the Chronological Age for the Mexican Sample

\begin{tabular}{|l|c|c|c|c|c|c|}
\hline \multicolumn{7}{|c|}{ Mexico } \\
\hline Difference & Bending & SAH & Ventral & BE+ & SAH+ & Suchey \\
& Energy & Score & Curvature & VC & VC & Brooks \\
& (BE) & & (VC) & & & \\
\hline$\leq 5$ & $32 \%$ & $26 \%$ & $37 \%$ & $29 \%$ & $23 \%$ & $37.5 \%$ \\
\hline 6 to 10 & 21 & 21 & 21 & 32 & 23 & 12.5 \\
\hline 11 to 15 & 0 & 16 & 5 & 13 & 26 & 12.5 \\
\hline$>15$ & 47 & 37 & 37 & 26 & 29 & 43.7 \\
\hline
\end{tabular}


Table 11. Mean Values for the Age Estimates for All Six Methods and the Spearman Rho Correlation between the Chronological Age and the Estimated Age for the Mexican Sample

\begin{tabular}{|c|c|c|c|}
\hline Age-at-Death & Mean & Correlation & Sign. Prob. \\
\hline Chronological Age & 53.05 & & \\
\hline Bending Energy & 36.30 & 0.234 & 0.306 \\
\hline SAH Score & 36.73 & 0.129 & 0.576 \\
\hline Ventral Curvature & 40.50 & 0.367 & 0.101 \\
\hline Ventral Curvature + Bending Energy & 38.38 & 0.287 & 0.205 \\
\hline Ventral Curvature + SAH & 36.78 & 0.293 & 0.196 \\
\hline Suchey Brooks & 38.46 & 0.739 & $0.000^{*}$ \\
\hline
\end{tabular}

$(*=$ significantly different with a $\alpha=0.05)$

Table 12. Bias and Inaccuracy Values Calculated for Each Method on the Mexican Sample

\begin{tabular}{|c|c|c|}
\hline Method & Bias & Inaccuracy \\
\hline Suchey Brooks & -9.27 & 13.07 \\
\hline Ventral Curvature & -12.54 & 20.57 \\
\hline SAH Score & -16.32 & 19.47 \\
\hline SAH Score + Ventral Curvature & -16.27 & 18.29 \\
\hline Bending Energy +Ventral Curvature & -14.66 & 19.64 \\
\hline Bending Energy & -16.74 & \\
\hline
\end{tabular}


Table 13. Summary of the Results for the BE Method, the SAH Score Method, and the VC Used in Univariate Regression Models

\begin{tabular}{|c|c|c|c|c|}
\hline \multicolumn{5}{|c|}{ Pooled sample (Mexico + Puerto Rico + Spain) } \\
\hline \multicolumn{5}{|c|}{ Bending Energy Method } \\
\hline Transformation & p-value & $\mathbf{R}^{2}$ & RMSE & Equation \\
\hline Age vs Score & $<0.0001 *$ & 0.09 & 15.00 & $\begin{array}{l}\mathrm{AGE}=48.732772- \\
2.8741794 * \mathrm{BEScore}\end{array}$ \\
\hline $\begin{array}{c}\text { Age vs } \\
\log (\text { Score })\end{array}$ & $<0.0001 *$ & 0.09 & 14.98 & $\begin{array}{c}\mathrm{AGE}=46.713853- \\
17.242095 * \operatorname{logBEScore}\end{array}$ \\
\hline \multicolumn{5}{|c|}{ SAH Score Method } \\
\hline Transformation & p-value & $\mathbf{R}^{2}$ & RMSE & Equation \\
\hline Age vs Score & 0.758 & 0.03 & 15.76 & $\begin{array}{l}\mathrm{AGE}=42.985822- \\
2.0155397 * \mathrm{SAHScore}\end{array}$ \\
\hline $\begin{array}{c}\text { Age vs } \\
\log (\text { Score })\end{array}$ & $<0.0001 *$ & 0.03 & 15.25 & $\begin{array}{c}\mathrm{AGE}=28.499029- \\
19.663995 * \log \mathrm{S} \text { AHScore }\end{array}$ \\
\hline \multicolumn{5}{|c|}{ Ventral Curvature Method } \\
\hline Transformation & p-value & $\mathbf{R}^{2}$ & RMSE & Equation \\
\hline Age vs Score & .186 & 0.06 & 15.71 & $\begin{array}{l}\mathrm{AGE}=40.418148+ \\
24.821881 * \text { VCScore }\end{array}$ \\
\hline $\begin{array}{c}\text { Age vs } \\
\log (\text { Score })\end{array}$ & $<0.0001^{*}$ & 0.04 & 15.41 & $\begin{array}{c}\mathrm{AGE}=58.653776+ \\
14.436573 * \log \mathrm{VCScore}\end{array}$ \\
\hline
\end{tabular}

$(*=$ significantly different with a $\alpha=0.05)$ 
Table 14. Summary of the Results of the Bending Energy Method, the SAH Score Method, and the Ventral Curvature Method Used in Univariate Regression Models for the Puerto Rican and Spanish Sample

\begin{tabular}{|c|c|c|c|c|}
\hline \multicolumn{5}{|c|}{ Puerto Rico + Spain } \\
\hline \multicolumn{5}{|c|}{ Bending Energy Method } \\
\hline Transformation & p-value & $\mathbf{R}^{2}$ & RMSE & Equation \\
\hline Age vs Score & $<0.0001 *$ & .09 & 14.02 & $\begin{array}{l}\mathrm{AGE}=48.752059- \\
3.342246 * \mathrm{BEScore}\end{array}$ \\
\hline $\begin{array}{l}\text { Age vs } \\
\log (\text { Score })\end{array}$ & $<0.0001 *$ & .09 & 14.17 & $\begin{array}{l}\mathrm{AGE}=45.858116- \\
16.50479 * \log \mathrm{BES} \text { core }\end{array}$ \\
\hline \multicolumn{5}{|l|}{ SAH Score Method } \\
\hline Transformation & p-value & $\mathbf{R}^{2}$ & RMSE & Equation \\
\hline Age vs Score & $<0.0001 *$ & .16 & 13.48 & $\begin{array}{l}\mathrm{AGE}=58.62323- \\
85.470048 * \text { SAHScore }\end{array}$ \\
\hline $\begin{array}{l}\text { Age vs } \\
\log (\text { Score })\end{array}$ & $<0.0001 *$ & .14 & 13.61 & $\begin{array}{l}\mathrm{AGE}=14.037731- \\
37.934785 * \log \mathrm{S} \text { AHScore }\end{array}$ \\
\hline \multicolumn{5}{|c|}{ Ventral Curvature Method } \\
\hline Transformation & p-value & $\mathbf{R}^{2}$ & RMSE & Equation \\
\hline Age vs Score & $0.032 *$ & .01 & 14.61 & $\begin{array}{l}\mathrm{AGE}=35.871585+ \\
69.039904 * \mathrm{VCScore}\end{array}$ \\
\hline $\begin{array}{l}\text { Age vs } \\
\log (\text { Score })\end{array}$ & $0.006^{*}$ & .03 & 14.53 & $\begin{array}{l}\mathrm{AGE}=55.865936+ \\
5.5405596 * \log \text { VCScore }\end{array}$ \\
\hline
\end{tabular}

$(*=$ significantly different with a $\alpha=0.05)$ 
Table 15. Bias and Inaccuracies for the New Regression Equations (Puerto Rico and Spain) Using the Mexican Sample

\begin{tabular}{|l|l|l|l|}
\hline & $\begin{array}{l}\text { Bending Energy } \\
\text { method }\end{array}$ & $\begin{array}{l}\text { Slice-Algee-Hewitt } \\
\text { method }\end{array}$ & $\begin{array}{l}\text { Ventral Curvature } \\
\text { method }\end{array}$ \\
\hline Bias & -8.49 & -6.09 & -8.75 \\
\hline Inaccuracy & 18.96 & 16.81 & 20.52 \\
\hline
\end{tabular}


Figure 1. Age distribution for the pooled sample (Mexico, Puerto Rico and Spain).

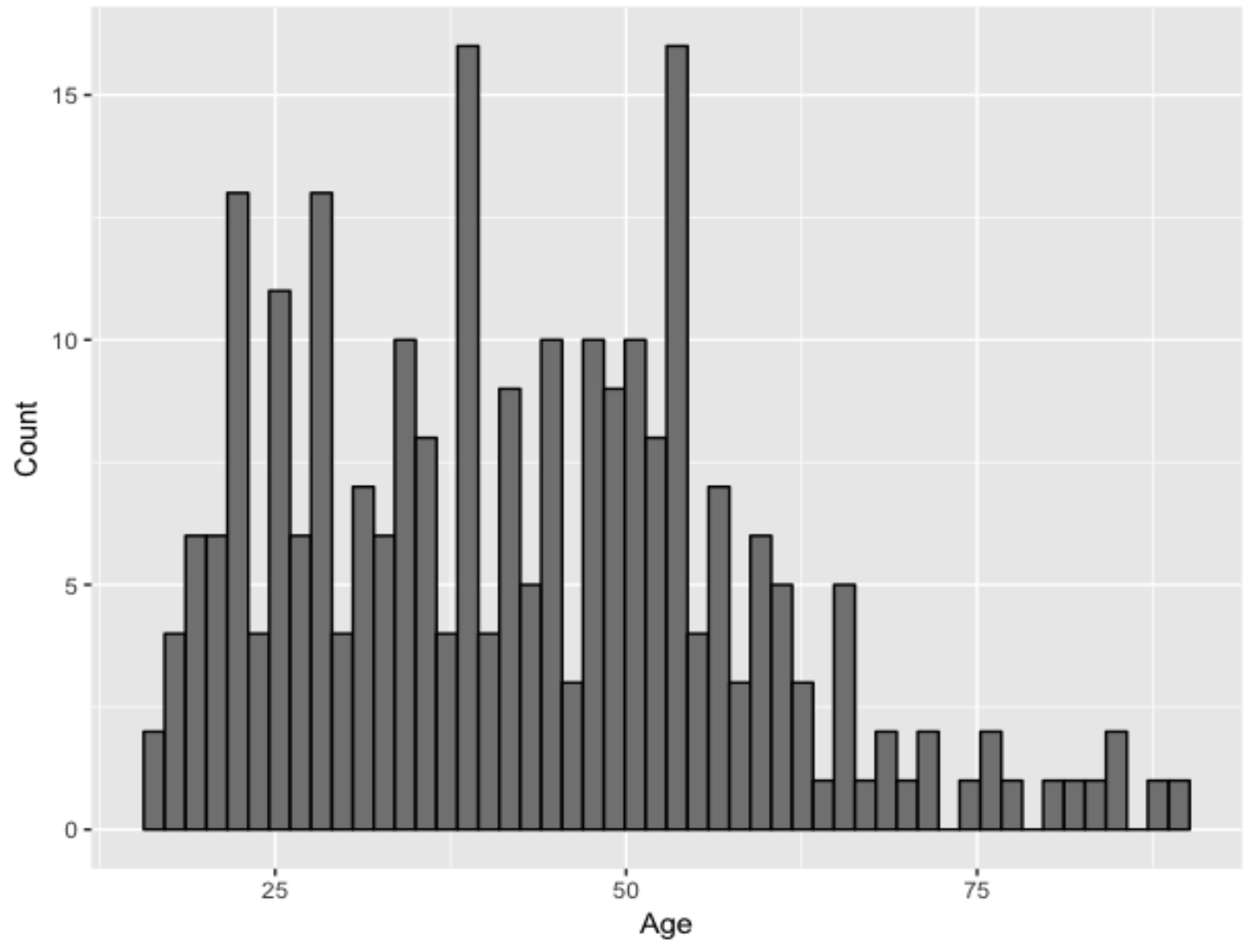

